\title{
Effectiveness of disease-management programs for improving diabetes care: a meta-analysis
}

\author{
Clément Pimouguet MSc, Mélanie Le Goff MSc, Rodolphe Thiébaut MD PhD, Jean François Dartigues MD PhD, \\ Catherine Helmer MD PhD
}

\begin{abstract}
Background: We conducted a meta-analysis of randomized controlled trials to assess the effectiveness of disease-management programs for improving glycemic control in adults with diabetes mellitus and to study which components of programs are associated with their effectiveness.
\end{abstract}

Methods: We searched several databases for studies published up to December 2009. We included randomized controlled trials involving adults with type 1 or 2 diabetes that evaluated the effect of disease-management programs on glycated hemoglobin (hemoglobin $A_{1 c}$ ) concentrations. We performed a meta-regression analysis to determine the effective components of the programs.

Results: We included 41 randomized controlled trials in our review. Across these trials, diseasemanagement programs resulted in a significant reduction in hemoglobin $A_{1 c}$ levels (pooled standardized mean difference between intervention and control groups -0.38 [95\% confidence interval -0.47 to -0.29$]$, which corresponds to an absolute mean difference of
$0.51 \%$ ). The finding was robust in the sensitivity analyses based on quality assessment. Programs in which the disease manager was able to start or modify treatment with or without prior approval from the primary care physician resulted in a greater improvement in hemoglobin $A_{1 C}$ levels (standardized mean difference -0.60 v. -0.28 in trials with no approval to do so; $p<0.001$ ). Programs with a moderate or high frequency of contact reported a significant reduction in hemoglobin $A_{1 c}$ levels compared with usual care; nevertheless, only programs with a high frequency of contact led to a significantly greater reduction compared with lowfrequency contact programs (standardized mean difference -0.56 v. $-0.30, p=0.03$ ).

Interpretation: Disease-management programs had a clinically moderate but significant impact on hemoglobin $A_{1 c}$ levels among adults with diabetes. Effective components of programs were a high frequency of patient contact and the ability for disease managers to adjust treatment with or without prior physician approval.
Competing interests: See end of article for competing interests.

This article has been peer reviewed.

Correspondence to:

Clément Pimouguet,

clement.pimouguet@ispe

.u-bordeaux 2 .fr

CMAJ 2011. DOI:10.1503 /cmaj.091786
$\mathrm{D}$ espite well-established recommendations for diabetes care, ${ }^{1-3}$ quality of care still needs to be improved. Although many nonpharmacologic strategies (patient education, psychological intervention, dietary education, self-monitoring and telemedicine) have been developed, their effectiveness is still unclear. ${ }^{4-6}$ "Disease management" is a structured, multifaceted intervention that includes several of the above-mentioned components. In two recent meta-analyses, disease management was associated with an improvement in glycemic control, as assessed by a mean reduction in hemoglobin $\mathrm{A}_{1 \mathrm{C}}$ concentration of $0.52 \%$ and $0.81 \%{ }^{7.8}$ Disease management seems to be more effective than single strategies such as clinician education, patient education or promotion of self-management.

Because disease-management programs are heterogeneous, the effective components need to be identified to improve program implementation.
Previous studies have evaluated the efficacy of some program components. ${ }^{78}$ Independent medication changes by the disease manager appear to be particularly effective. ${ }^{?}$ However, other important factors such as the intensity of the intervention have not been previously evaluated.

We conducted a meta-analysis of randomized controlled trials (RCTs) involving adults with type 1 or 2 diabetes mellitus that evaluated the effect of disease-management programs on hemoglobin $\mathrm{A}_{\mathrm{IC}}$ levels. We determined the effective components of the programs, considering both the type of component and the intensity of the intervention.

\section{Methods}

\section{Definition of disease management}

There is no consensual definition of disease management. According to the Care Continuum 
Alliance (formerly the Disease Management Association of America), disease management "supports the physician or practitioner/patient relationship and plan of care; emphasizes prevention of exacerbations and complications utilizing evidence-based practice guidelines and patient empowerment strategies; and evaluates clinical, humanistic, and economic outcomes on an on-going basis with the goal of improving overall health" (www.carecontinuum.org/dm _definition.asp). To identify relevant studies for our meta-analysis, we adopted an operational definition based on the above definition, literature review and expert opinion.

We defined disease management as ongoing and proactive follow-up of patients that includes at least two of the following five components: patient education (dietary and exercise counselling, self-monitoring, and knowledge of disease and medication); coaching (the disease manager encourages the patient to overcome psychological or social barriers that impede autonomy or improvement in medication compliance); treatment adjustment (the disease manager is able to start or modify treatment with or without prior approval from the primary care physician); monitoring (the disease manager gets medical data from the patient); and care coordination (the disease manager reminds the patient about upcoming appointments or important aspects of self-care and informs the primary care physician about complications, treatment adjustment or therapeutic recommendations).

\section{Literature search}

We searched the following computerized databases: MEDLINE (1966 to December 2009), Scopus (1960 to December 2009), Web of Science (1975 to December 2009) and the Cochrane Library (1993 to 2009 [issue 4]) The complete MEDLINE search strategy is presented in Appendix 1 (available at www.cmaj.ca/cgi/content/full /cmaj.091786/DC1). In an attempt to minimize the omission of potentially relevant trials, we also searched the reference lists of included studies. We used the terms "patient care team," "disease management," "case management," "managed care programs," "home-based intervention" and "patient care management" to cover the inconsistency in the definition of disease management; we also used the terms "diabetes mellitus," " $\mathrm{HbA}_{\mathrm{c}}$ " and "glycated hemoglobin."

Two of us (C.P. and C.H.) first reviewed the titles and abstracts of identified articles and then examined the full-text version of selected articles further to assess relevance to the research topic. Only RCTs were included, because this study design supports maximum validity and causal inference. ${ }^{9}$ The search was limited to Englishlanguage publications. We restricted inclusion to studies that reported hemoglobin $\mathrm{A}_{1 \mathrm{C}}$ levels, which is an index of the mean blood glucose concentration of the preceding $8-12$ weeks..$^{10}$ In addition to our operational definition of disease management, we defined the following inclusion criteria: the study had to involve adults with type 1 or 2 diabetes; it had to report both pre- and postintervention hemoglobin $\mathrm{A}_{1 \mathrm{C}}$ levels; and postintervention hemoglobin $A_{1 C}$ levels had to be assessed after at least 12 weeks of follow-up.

We excluded trials in which the intervention did not involve direct contact between the disease manager and the patient or was unclear, unspecified or exclusively based on contact by Internet or mail.

\section{Data extraction}

Two of us (C.P. and C.H.) evaluated each study separately and extracted data. To assess outcome, hemoglobin $\mathrm{A}_{\mathrm{IC}}$ levels before and after the intervention were extracted. In the event of several postintervention values, only the first one was considered. Other data extracted were as follows: characteristics of the participants (percentage of women, mean age), sample size, number of dropouts, intervention mode (one-to-one session, phone contact or both), type of program components (patient education, psychological coaching, monitoring, feedback of initial evaluation to primary care physician, treatment adjustment), length of intervention, frequency of contact, interval between pre- and postintervention hemoglobin $\mathrm{A}_{\mathrm{IC}}$ assessments, and adverse events (hypoglycemic episodes, hospital admission and death).

Frequency of contact was estimated on the basis of the reported intervention protocol and, when available, the results. We classified the frequency into three levels: low (less than one contact monthly per patient), moderate (one contact monthly per patient) and high (several contacts monthly per patient). In the event of discrepancies in the classification of contact frequency, data were reviewed by another one of us (M.L.G.), and a consensus was reached.

When data were missing, the original authors of the article were contacted by email.

\section{Statistical analysis}

To account for differences in baseline hemoglobin $A_{1 C}$ levels between the studies, we calculated the mean difference between pre- and postintervention hemoglobin $A_{1 C}$ levels for the intervention and control groups, and the standard deviation (SD) of each difference. Thus, our outcome corresponds to the improvement in glycemic control in the intervention group between base- 
line and postintervention hemoglobin $\mathrm{A}_{1 \mathrm{C}}$ levels compared with the control group. We used the imputation method according to baseline values for missing SDs (we imputed missing SDs according to the pre-intervention values). Owing to significant heterogeneity, we used a randomeffects model to calculate the pooled standardized mean difference in hemoglobin $\mathrm{A}_{1 \mathrm{C}}$ levels between the intervention and control groups, along with the $95 \%$ confidence interval (CI). ${ }^{11}$ Heterogeneity was quantified by using $I^{2}$ and $\tau^{2}$ (study variance) values. ${ }^{12,13}$

We used meta-regression analysis to determine what part of between-study variance was explained by patient characteristics (mean hemoglobin $\mathrm{A}_{1 \mathrm{c}}$ level, age, sex) and components of the disease-management programs (length of intervention, treatment adjustment, mode of patient education, frequency of contact, feedback of initial evaluation to primary care physician, and mode of intervention). Results are expressed as standardized mean changes in the hemoglobin $\mathrm{A}_{1 \mathrm{C}}$ level. Explained heterogeneity was expressed as a percentage change of $\tau^{2}$ (between-study variance).

Because quality assessment in meta-analysis is controversial, ${ }^{14}$ we performed three sensitivity analyses based on key components of internal validity to test the robustness of our results. ${ }^{15} \mathrm{In}$ the first sensitivity analysis, we excluded trials that had a dropout rate of $20 \%$ or more and trials without dropout information. In the second analysis, we excluded trials in which the difference in dropout rates between study groups was $7 \%$ or more (highest quintile) and trials without dropout information. In the third analysis, we excluded trials with unclear information about allocation concealment. ${ }^{16}$

For all analyses, a $p$ value of 0.05 or less was considered to be statistically significant.

\section{Results}

\section{Study characteristics}

The selection of studies for our review is summarized in Figure $1 .{ }^{17}$ The initial search strategy identified 2148 citations, and 135 full-text articles were reviewed. Forty-four studies met our inclusion criteria. Three studies were excluded because of missing data on hemoglobin $A_{1 C}$ levels at baseline, even after contacting the authors. ${ }^{18-20}$ Thus, we included 41 RCTs published between 1990 and 2009 that enrolled a total of 7013 adults with type 1 or 2 diabetes..$^{21-61}$

The main features of the 41 RCTs are shown in Table 1 (at the end of the article). Twenty-six trials were conducted in the United States, five in Canada, three in Europe and seven in Asia. Sam- ple sizes ranged from 31 to 1665 . The length of the intervention ranged from 1.5 to 48 months. In most trials, the length of intervention and the length of follow-up were similar, with only five trials reporting a few months' difference between the end of the intervention and hemoglobin $A_{1 C}$ assessment. ${ }^{21,23,29,39,49}$ Most of the studies (29 trials) focused solely on type 2 diabetes, 9 included patients with either type 1 or 2 diabetes, and 3 trials focused on type 1 diabetes. The mean age of the participants was 57.6 years (SD 7.3); $46.0 \%$ were men. The mean hemoglobin $\mathrm{A}_{1 \mathrm{C}}$ concentration at baseline was $8.5 \%$ (SD 1.4\%).

\section{Effect of intervention on glycemic control}

The impact of the disease-management programs on changes in hemoglobin $A_{1 C}$ concentrations in the intervention and control groups is presented in Figure 2. In the random-effects model, the pooled standardized mean difference in levels between the intervention and control groups was -0.38 (95\% CI -0.47 to $-0.29 ; p<0.001$ ), favouring disease

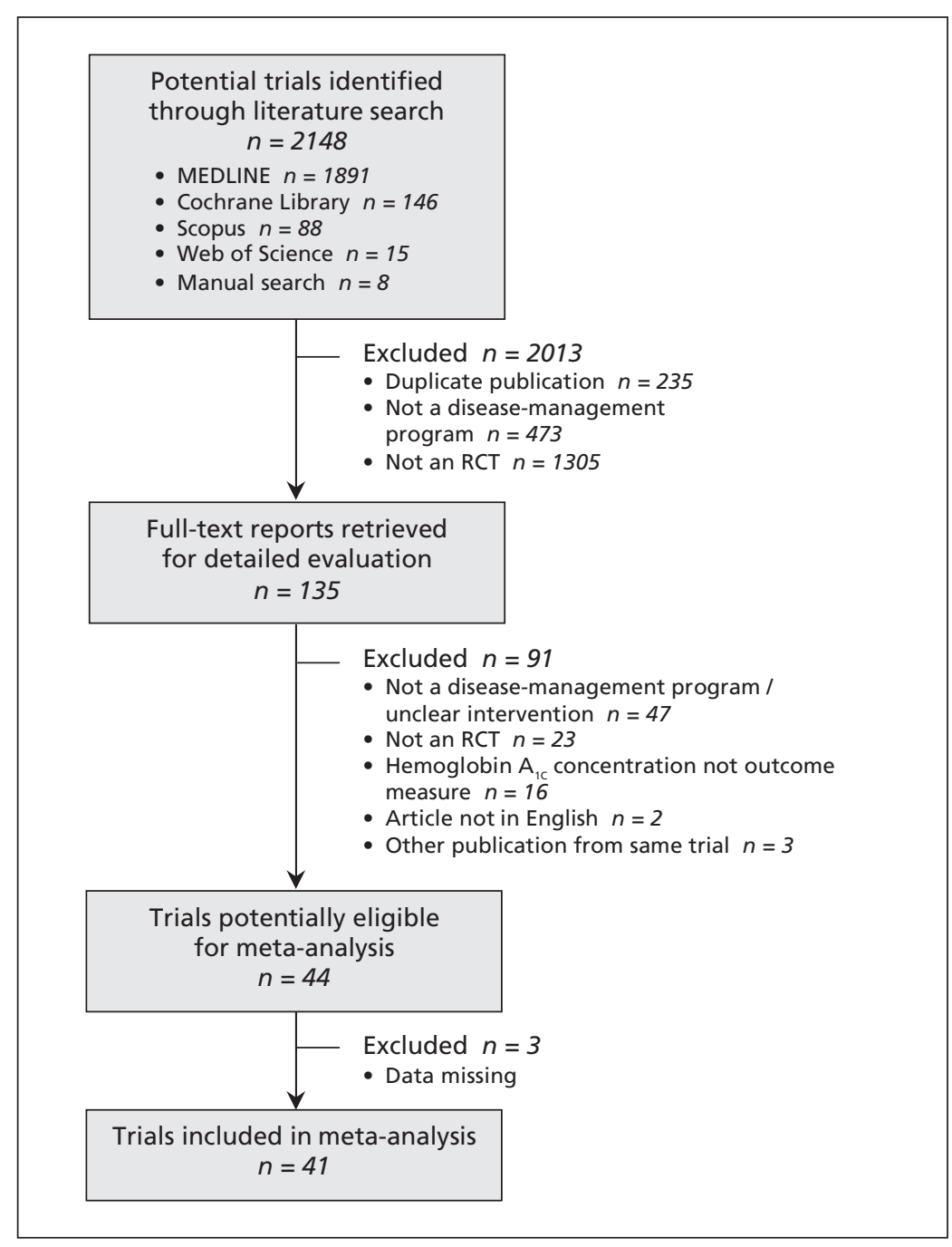

Figure 1: Selection of randomized controlled trials (RCTs) for the meta-analysis. 
management over usual care. This standardized mean difference corresponds to an absolute mean difference in hemoglobin $\mathrm{A}_{1 \mathrm{C}}$ levels of $0.51 \%$ between the intervention and control groups. None of the studies reported a significant change in hemoglobin $A_{1 C}$ in favour of usual care. There was significant heterogeneity among the trials regarding changes in hemoglobin $\mathrm{A}_{1 \mathrm{C}}\left(I^{2}=66 \%\right){ }^{62}$
Meta-regression and subgroup analyses

Results of univariable meta-regression analyses, stratified by patient characteristics and components of the disease-management programs, are shown in Table 2. Of the patient characteristics analyzed, age and sex were not associated with between-group differences in hemoglobin $\mathrm{A}_{1 \mathrm{C}}$ outcomes. The reduction in hemoglobin $\mathrm{A}_{1 \mathrm{C}}$ lev-

\begin{tabular}{|c|c|c|c|c|c|c|}
\hline \multirow[b]{2}{*}{ Study } & \multicolumn{2}{|c|}{ Mean change in $\mathrm{HbA}_{1 c^{\prime}} \%$} & \multirow{2}{*}{$\begin{array}{l}\text { Standardized mean } \\
\text { difference between } \\
\text { groups }(95 \% \mathrm{Cl})\end{array}$} & & \multirow{2}{*}{$\longleftarrow \begin{array}{r}\text { Favours disease } \\
\text { management }\end{array}$} & \multirow{2}{*}{$\begin{array}{l}\text { Favours usual } \\
\text { care } \longrightarrow\end{array}$} \\
\hline & Intervention & Control & & & & \\
\hline Ahring et al..$^{22}$ & -1.4 & -1.0 & $-0.17(-0.81$ to 0.47$)$ & & & - \\
\hline Choe et al. ${ }^{44}$ & -2.1 & -0.9 & $-0.52(-1.02$ to -0.02$)$ & & & \\
\hline Dale et al. ${ }^{58}$ & -0.9 & -0.8 & $-0.07(-0.46$ to 0.32$)$ & & & \\
\hline Doucette et al. ${ }^{59}$ & -0.3 & 0.1 & $-0.27(-0.76$ to 0.21$)$ & & & \\
\hline Estey et al. ${ }^{21}$ & -0.7 & -0.3 & $-0.49(-1.03$ to 0.06$)$ & & & \\
\hline Farmer et al. ${ }^{45}$ & -0.6 & -0.4 & $-0.16(-0.60$ to 0.28$)$ & & & \\
\hline Franz et al. ${ }^{23}$ & -1.1 & -0.8 & $-0.20(-0.49$ to 0.09$)$ & & & \\
\hline Fukuda et al. ${ }^{26}$ & -0.2 & -0.2 & $0.00(-0.55$ to 0.55$)$ & & & \\
\hline Gabbay et al..$^{50}$ & -0.1 & 0.0 & $-0.03(-0.25$ to 0.18$)$ & & & \\
\hline Gaede et al. ${ }^{27}$ & -0.8 & 0.2 & $-0.57(-0.89$ to -0.24$)$ & & & \\
\hline Gary et al. ${ }^{38}$ & -1.0 & -0.2 & $-0.79(-1.28$ to -0.30$)$ & & & \\
\hline Goudswaard et al. ${ }^{39}$ & -1.0 & -0.4 & $-0.47(-1.01$ to 0.07$)$ & & & \\
\hline Hiss et al. ${ }^{32}$ & -0.3 & -0.2 & $-0.08(-0.32$ to 0.16$)$ & & & \\
\hline Hiss et al. ${ }^{54}$ & -0.4 & -0.2 & $-0.14(-0.44$ to 0.17$)$ & & & \\
\hline Jaber et al..$^{25}$ & -2.2 & -0.1 & $-0.73(-1.38$ to -0.07$)$ & & & \\
\hline CMD Study ${ }^{40}$ & -1.9 & -1.2 & $-0.50(-0.72$ to -0.27$)$ & & & \\
\hline Kim et al. ${ }^{60}$ & -1.3 & -0.4 & $-0.66(-1.11$ to -0.21$)$ & & $\perp$ & \\
\hline Ko et al. ${ }^{41}$ & -0.5 & -0.2 & $-0.24(-0.53$ to 0.06$)$ & & & \\
\hline Ko et al..$^{55}$ & -1.5 & -0.5 & $-0.80(-1.03$ to -0.57$)$ & & 1 & \\
\hline Krein et al..$^{42}$ & 0.0 & 0.0 & $0.00(-0.27$ to 0.27$)$ & & & \\
\hline Litaker et al..$^{34}$ & -0.6 & -0.1 & $-0.39(-0.71$ to -0.07$)$ & & & \\
\hline McMahon et al. ${ }^{47}$ & -1.6 & -1.2 & $-0.28(-0.71$ to 0.14$)$ & & & \\
\hline Montori et al. ${ }^{43}$ & -1.3 & -0.6 & $-0.59(-1.35$ to 0.17$)$ & & & \\
\hline Ménard et al. ${ }^{46}$ & -1.6 & -0.7 & $-0.71(-1.20$ to -0.22$)$ & & 1 & \\
\hline Oh et al..$^{35}$ & -1.2 & 0.6 & $-1.26(-1.96$ to -0.56$)$ & & 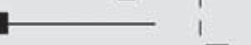 & \\
\hline Piette et al. ${ }^{33}$ & -0.6 & -0.3 & $-0.30(-0.57$ to -0.03$)$ & & & \\
\hline Piette et al. ${ }^{31}$ & -0.1 & 0.1 & $-0.13(-0.37$ to 0.11$)$ & & & \\
\hline Polonsky et al. ${ }^{36}$ & -2.3 & -1.7 & $-0.30(-0.66$ to 0.07$)$ & & & \\
\hline Ridgeway et al. ${ }^{28}$ & -0.8 & -0.7 & $-0.04(-0.67$ to 0.60$)$ & & & \\
\hline Rothman et al. ${ }^{48}$ & -2.5 & -1.6 & $-0.45(-0.73$ to -0.16$)$ & & & \\
\hline Sadur et al. ${ }^{29}$ & -1.2 & -0.3 & $-0.69(-1.01$ to -0.37$)$ & & + & \\
\hline Samuel-Hodge et al. ${ }^{61}$ & -0.3 & -0.2 & $-0.08(-0.39$ to 0.22$)$ & & & \\
\hline Scott et al..$^{51}$ & -1.7 & -0.7 & $-0.99(-1.36$ to -0.63$)$ & & 1 & \\
\hline Shea et al..$^{52}$ & -0.4 & -0.2 & $-0.13(-0.23$ to 0.04$)$ & & & \\
\hline Shibayama et al..$^{53}$ & -0.1 & 0.0 & $-0.08(-0.26$ to 0.42$)$ & & & \\
\hline Sun et al. ${ }^{57}$ & -0.8 & -0.1 & $-0.54(-0.89$ to -0.19$)$ & & & \\
\hline Taylor et al. ${ }^{37}$ & -1.1 & -0.3 & $-0.66(-1.02$ to -0.30$)$ & & & \\
\hline Taylor et al. ${ }^{49}$ & -0.3 & 0.7 & $-0.70(-1.35$ to -0.05$)$ & & 1 & \\
\hline Thompson et al..$^{30}$ & -1.8 & -0.5 & $-0.98(-1.59$ to -0.37$)$ & & - & \\
\hline Wattana et al. ${ }^{56}$ & -0.7 & -0.1 & $-0.50(-0.83$ to -0.17$)$ & & & \\
\hline Weinberger et al. ${ }^{24}$ & -0.2 & 0.4 & $-0.30(-0.59$ to -0.01$)$ & & & \\
\hline \multirow[t]{3}{*}{ Overall $\left(I^{2}=66 \%\right)$} & -0.62 & -0.25 & $-0.38(-0.47$ to -0.29$)$ & & $<$ & \\
\hline & & & & -2 & & 1 \\
\hline & & & & \multicolumn{3}{|c|}{ Standardized mean difference $(95 \% \mathrm{Cl})$} \\
\hline
\end{tabular}

Figure 2: Estimated differences in hemoglobin $A_{1 c}$ level before and after intervention of disease management for improved glycemic control in adults with type 1 or 2 diabetes mellitus. Standardized mean differences between intervention and control groups of less than zero indicate an effect in favour of disease-management programs. $\mathrm{Cl}$ = confidence interval, CMD study = California Medi-Cal Type 2 Diabetes Study. 
els was significantly greater among patients with a baseline hemoglobin $\mathrm{A}_{1 \mathrm{C}}$ level of $8.0 \%$ or higher (standardized mean difference -0.45) than among those with a baseline level of less than $8.0 \%$ (standardized mean difference -0.14) $(p=0.003)$. About $33 \%$ of the variance between trials could be explained by mean hemoglobin $\mathrm{A}_{1 \mathrm{C}}$ values at baseline.

Two components of the disease-management programs led to greater improvements in glycemic control (Table 2). First, programs in which the disease manager was able to start or modify treatment with or without prior approval from the primary care physician resulted in a significantly greater reduction in hemoglobin $\mathrm{A}_{\mathrm{IC}}$ levels (standardized mean difference -0.60 v. -0.28 in trials with no approval to do so; $p<0.001)$. Second, among the 36 trials that reported sufficient information to allow classification of the frequency of patient contact (Table 1), programs with a moderate or high frequency of contact (28 trials) reported a significant reduction in hemoglobin $A_{1 C}$ levels compared with usual care (standardized mean difference -0.56 for high frequency and

Table 2: Effect of patient characteristics and components of disease-management programs on changes in hemoglobin $A_{1 c}$ concentration

\begin{tabular}{|c|c|c|c|c|c|}
\hline Variable & $\begin{array}{l}\text { No. of } \\
\text { studies }\end{array}$ & $\begin{array}{c}\text { Standardized mean } \\
\text { difference in change of } \\
\text { hemoglobin } \mathrm{A}_{\mathrm{c}} \text { between } \\
\text { intervention and control } \\
\text { groups }(95 \% \mathrm{Cl})\end{array}$ & $\begin{array}{l}p \text { value for } \\
\text { difference } \\
\text { in effect* }\end{array}$ & $\begin{array}{l}\text { Heterogeneity, } \uparrow \\
I^{2}(95 \% \mathrm{Cl}), \%\end{array}$ & $\begin{array}{c}\text { Variance } \\
\text { between studies } \\
\text { explained by } \\
\text { variable, } \%\end{array}$ \\
\hline \multicolumn{6}{|l|}{ Patient characteristic } \\
\hline Mean $\mathrm{HbA}_{1 \mathrm{c}}$ level at baseline & $40 \ddagger$ & & & & 32.7 \\
\hline$<8.0 \%$ & 11 & $-0.14(-0.25$ to -0.05$)$ & & 25 (0 to 63) & \\
\hline$\geq 8.0 \%$ & 29 & $-0.45(-0.56$ to -0.34$)$ & 0.003 & 59 (38 to 73 ) & \\
\hline Age & $36 \ddagger$ & $0.01(-0.01$ to 0.02$)$ & 0.23 & & 22.2 \\
\hline Sex & $39 \ddagger$ & $0.00(-0.01$ to 0.01$)$ & 0.30 & & 4.6 \\
\hline \multicolumn{6}{|c|}{$\begin{array}{l}\text { Component of disease-management } \\
\text { program }\end{array}$} \\
\hline Treatment adjustment & 41 & & & & 39.2 \\
\hline No (ref) & 28 & $-0.28(-0.37$ to -0.18$)$ & & 60 (39 to 73 ) & \\
\hline Yes & 13 & $-0.60(-0.73$ to -0.47$)$ & $<0.001$ & 28 (0 to 63$)$ & \\
\hline Patient education & $39 \neq$ & & & & 31.9 \\
\hline Individual (ref) & 31 & $-0.32(-0.41$ to -0.23$)$ & & 54 (31 to 69$)$ & \\
\hline Group + individual & 8 & $-0.48(-0.68$ to -0.28$)$ & 0.11 & 65 (25 to 84$)$ & \\
\hline Intervention mode & 41 & & & & 10.7 \\
\hline Phone (ref) & 10 & $-0.27(-0.42$ to -0.12$)$ & & 53 (5 to 77 ) & \\
\hline Face to face + phone & 18 & $-0.47(-0.63$ to -0.32$)$ & 0.12 & 71 (54 to 82 ) & \\
\hline Face to face & 13 & $-0.30(-0.43$ to -0.16$)$ & 0.90 & 39 (0 to 68$)$ & \\
\hline Length of intervention, mo & 41 & & & & 7.5 \\
\hline$<12$ (ref) & 19 & $-0.48(-0.63$ to -0.33$)$ & & 53 (21 to 72$)$ & \\
\hline$\geq 12$ & 22 & $-0.31(-0.42$ to -0.20$)$ & 0.08 & 69 (52 to 80$)$ & \\
\hline Frequency of contact & $36 \ddagger$ & & & & 6.1 \\
\hline Low (ref) & 8 & $-0.30(-0.54$ to 0.06$)$ & & 80 (62 to 90$)$ & \\
\hline Moderate & 12 & $-0.24(-0.37$ to -0.12$)$ & 0.73 & 33 (0 to 66$)$ & \\
\hline High & 16 & $-0.56(-0.72$ to -0.40$)$ & 0.033 & 52 (14 to 73 ) & \\
\hline $\begin{array}{l}\text { Feedback of initial evaluation to } \\
\text { primary care physician }\end{array}$ & 41 & & & & 3.4 \\
\hline Yes (ref) & 21 & $-0.33(-0.44$ to -0.22$)$ & & 67 (49 to 79 ) & \\
\hline No & 20 & $-0.44(-0.59$ to -0.29$)$ & 0.26 & 58 (31 to 74$)$ & \\
\hline
\end{tabular}


Table 3: Components of quality assessment that were considered for the sensitivity analyses

\begin{tabular}{|c|c|c|c|}
\hline Study & $\begin{array}{l}\text { Dropout } \\
\text { rate, } \%\end{array}$ & $\begin{array}{c}\text { Difference in } \\
\text { dropout rates } \\
\text { between study } \\
\text { groups, \% }\end{array}$ & $\begin{array}{c}\text { Allocation } \\
\text { concealment }\end{array}$ \\
\hline
\end{tabular}

\begin{tabular}{|lrrr|}
\hline Estey et al. $^{21}$ & 11.7 & NA & B \\
\hline Ahring et al. ${ }^{22}$ & 9.5 & 2.1 & B \\
\hline
\end{tabular}

\begin{tabular}{|lrrl|}
\hline Franz et al. ${ }^{23}$ & 27.5 & NA & B \\
\hline Weinberger et al. ${ }^{24}$ & 8.7 & 3.4 & B \\
\hline Jaber et al. ${ }^{25}$ & 13.3 & 26.1 & B
\end{tabular}

\begin{tabular}{|c|c|c|c|}
\hline Jaber et al. & 13.3 & 26.1 & B \\
\hline Fukuda et al. ${ }^{26}$ & 3.8 & 3.0 & B \\
\hline Gaede et al. ${ }^{27}$ & 6.9 & 3.7 & $A$ \\
\hline Ridgeway et al. ${ }^{28}$ & 32.1 & 7.1 & B \\
\hline Sadur et al. ${ }^{29}$ & 15.7 & 4.4 & B \\
\hline Thompson et al. ${ }^{30}$ & 0 & 0 & A \\
\hline Piette et al. ${ }^{31}$ & 11.4 & 3.8 & $A$ \\
\hline Hiss et al. ${ }^{32}$ & 27.4 & 3.7 & B \\
\hline
\end{tabular}

\begin{tabular}{|c|c|c|c|}
\hline Hiss et al. ${ }^{32}$ & 27.4 & 3.7 & B \\
\hline Piette et al. ${ }^{33}$ & 6.2 & 5.5 & A \\
\hline Litaker et al. ${ }^{34}$ & NA & NA & B \\
\hline Oh et al. ${ }^{35}$ & 24.0 & 8.0 & B \\
\hline Polonsky et al. ${ }^{36}$ & 39.8 & 13.5 & B \\
\hline Taylor et $\mathrm{al}^{37}$ & 24.8 & 5.0 & B \\
\hline Gary et al. ${ }^{38}$ & 23.9 & 1.0 & A \\
\hline $\begin{array}{l}\text { Goudswaard } \\
\text { et al. }{ }^{39}\end{array}$ & 13.8 & 1.0 & A \\
\hline CMD Study ${ }^{40}$ & 12.4 & 7.0 & A \\
\hline
\end{tabular}

\begin{tabular}{|c|c|c|c|}
\hline CMD Study $^{40}$ & 12.4 & 7.0 & A \\
\hline Ko et al. ${ }^{41}$ & 1.1 & 2.2 & B \\
\hline Krein et al. ${ }^{42}$ & 15.0 & 2.3 & B \\
\hline Montori et al. ${ }^{43}$ & 9.7 & 7.1 & A \\
\hline Choe et al. ${ }^{44}$ & 18.7 & 13.4 & B \\
\hline Farmer et al. ${ }^{45}$ & 12.9 & 8.9 & A \\
\hline Ménard et al. ${ }^{46}$ & 4.2 & 2.8 & A \\
\hline McMahon et al. ${ }^{47}$ & 19.2 & 7.7 & A \\
\hline Rothman et al. ${ }^{48}$ & 10.6 & 2.1 & A \\
\hline Taylor et al. ${ }^{49}$ & 2.5 & 0.05 & B \\
\hline Gabbay et al. ${ }^{50}$ & NA & NA & B \\
\hline Scott et al..$^{51}$ & 12.1 & 12.8 & B \\
\hline Shea et al. ${ }^{52}$ & 14.9 & 4.4 & B \\
\hline Shibayama et al..$^{53}$ & 10.4 & 3.0 & B \\
\hline Hiss et al. ${ }^{54}$ & 16.7 & 3.9 & B \\
\hline Ko et al. ${ }^{55}$ & 29.5 & 5.2 & A \\
\hline Wattana et al. ${ }^{56}$ & 6.4 & 2.6 & B \\
\hline Sun et al. ${ }^{57}$ & 2.7 & 0.0 & B \\
\hline Dale et al. ${ }^{58}$ & 12.8 & 4.6 & $A$ \\
\hline Doucette et al. ${ }^{59}$ & 15.4 & 2.8 & B \\
\hline Kim et al. ${ }^{60}$ & 4.8 & 2.3 & B \\
\hline $\begin{array}{l}\text { Samuel-Hodge } \\
\text { et al. }{ }^{61}\end{array}$ & 15.4 & 4.2 & A \\
\hline
\end{tabular}

Note: $\mathrm{A}=$ adequate, $\mathrm{B}=$ unclear, CMD Study = California Medi-Cal Type 2 Diabetes Study, $\mathrm{NA}=$ not available.
-0.24 for moderate frequency). Nevertheless, only programs with a high frequency of contact led to a significantly greater reduction in hemoglobin $\mathrm{A}_{\mathrm{lC}}$ levels compared with programs with a low frequency of contact (standardized mean difference $-0.56 \mathrm{v}$. $-0.30, p=0.03$ ).

In the random-effects subgroup analyses, none of the other program components modified the effectiveness of the intervention on hemoglobin $\mathrm{A}_{1 \mathrm{C}}$ levels. Two components explained a large part of the variance between trials: $31.9 \%$ was ex plained by mode of education and $39.2 \%$ by treatment adjustment. Trials in which the disease manager was able to start or modify treatment with or without prior approval of the physician, trials with face-to-face sessions and trials with a moderate frequency of patient contact each showed a low level of heterogeneity $\left(I^{2}<50 \%\right)$.

\section{Sensitivity analyses}

Our primary findings did not change after we excluded trials with dropout rates of $20 \%$ or more and trials without dropout information (Table 3). The same was true after we excluded trials with a between-group difference in dropout rates of $7 \%$ or more and trials without dropout information, and after we excluded trials with unclear allocation concealment (Table 3).

\section{Adverse events}

Hypoglycemic episodes were not systematically assessed. Only 9 of the 41 studies reported this information separately for intervention and control groups, but with varied definitions of hypoglycemic episodes. ${ }^{22,25,27,31,40,43,45-47}$ No difference in hypoglycemic episodes between study groups was reported in six of the nine trials. In two of the three trials that reported a difference, the adverse event occurred more frequently in the control groups than in the intervention groups. ${ }^{31,45}$ Twenty studies reported deaths over the follow-up period; no overall difference in mortality between groups was found $(p=0.18)$. Hospital admissions were not clearly or systematically reported.

\section{Interpretation}

Our meta-analysis suggests that disease-management programs have a favourable effect on improving glycemic control, with a pooled standardized mean reduction of 0.38 (corresponding to a pooled absolute mean reduction of $0.51 \%$ ) in hemoglobin $\mathrm{A}_{1 \mathrm{C}}$ levels compared with usual care. This finding was robust in sensitivity analyses based on quality assessment. The United Kingdom Prospective Diabetes Study showed that each $1 \%$ reduction in hemoglobin $\mathrm{A}_{1 \mathrm{C}}$ level was associated with a $37 \%$ decrease in the risk of 
microvascular complications and a $21 \%$ decrease in the risk of death related to diabetes, with no evidence of a threshold. ${ }^{63}$ Therefore, the absolute reduction of $0.51 \%$ in hemoglobin $\mathrm{A}_{1 \mathrm{C}}$ level in our study appears to be clinically significant. Moreover, this finding is probably largely underestimated, because the usual care provided in control groups in RCTs is often better than that provided in clinical practice. Indeed, there was a significant standardized mean reduction in hemoglobin $A_{1 C}$ levels of -0.25 in the control groups, which corresponds to an absolute mean reduction of $0.40 \%$. Some studies included in our metaanalysis permitted patients in the control group to contact the medical team or be contacted by them during follow-up in addition to usual care. ${ }^{23,43,55}$ Also, patients received structured individual education before randomization in some trials. ${ }^{21,23}$

Our findings suggest that disease-management programs are more effective for patients who have poor glycemic control (mean hemoglobin $\mathrm{A}_{1 \mathrm{C}}$ $\geq 8.0 \%$ at baseline) than for those with better glycemic control. This is concordant with results among patients starting insulin therapy. ${ }^{64}$ Thus, disease management could be particularly effective if targeted at patients with nonstabilized diabetes. Moreover, such patients have a higher risk of complications and so would probably derive greater long-term benefit from disease management.

We found that the ability of disease managers to start or modify medical treatment was an effective feature of disease-management programs. This confirms the findings of Shojania and colleagues, who evaluated the ability to adjust treatment without prior physician agreement. ${ }^{7}$ However, we found that the ability to adjust treatment was an effective feature both with and without prior physician agreement, which is more relevant for physicians, nurses and pharmacists in clinical practice. This has important implications, because nonadherence to medical treatment is a significant predictor of all-cause mortality and hospital admission among patients with diabetes. ${ }^{65}$

Despite its relevance for clinicians and policymakers, the intensity of disease-management programs has not been investigated in previous reviews. Program intensity depends on the frequency of patient contacts, their duration and the length of the program. Because the duration of contact was not reported in most of the studies in cluded in our review, we were not able to explore it. However, we explored frequency of contact and length of intervention. We did not find any significant difference associated with length of intervention, despite a nonsignificant improvement observed with shorter interventions. Frequency of contact proved to be a key feature of the effectiveness of disease-management programs. There was substantial discrepancy in frequency across trials, ranging from "counseling by telephone every week if necessary" 22 to "at least five visits by the nurse within a study period of one year." ${ }^{41}$ For our analysis, frequency of contact was estimated on the basis of the intervention protocol reported and, when available, the results. Although the reported intervention protocol probably overestimated the real frequency of contact, frequency was evaluated on the basis of results in 12 studies and was consequently found to be an effective measure. Our findings are consistent with those from a recent large controlled trial, although it showed a nonsignificant trend toward better glycemic control with more intensive intervention. ${ }^{20}$ The greater effectiveness associated with a high frequency of patient contact suggests that only disease-management programs with intensive interventions should be implemented, perhaps by targeting patients at high risk of diabetes complications.

Patient education is the cornerstone of diabetes care. An overall beneficial effect of education among patients with diabetes has already been shown in several studies. ${ }^{6,67} \mathrm{We}$ did not find any difference in effectiveness between individual education and a combination of individual and group education. This finding suggests that a combination of group and individual education could be a solution to cope with the lack of medical providers and the time-consuming aspect of individual education. Surprisingly, neither the mode of contact nor feedback of the initial evaluation to the primary care physician were discriminatory components. However, we cannot rule out the possibility of incorrect classification of feedback as a program component, because it was taken for granted that such feedback would be provided systematically, so this step was not stipulated formally in the protocol.

\section{Strengths and limitations}

The strengths of the study include a comprehensive systematic review of the literature, with a large number of studies included. We used a broad search strategy to capture all relevant information. Our work confirms the findings of previous reviews, with a mean difference in hemoglobin $A_{1 C}$ level similar to that observed in previous studies. ${ }^{7,868,69}$ However, we included only RCTs and several more recent studies, with thus a larger sample size. Therefore, our estimate is probably more precise than that in previous studies.

Our study has limitations. Our analyses were based on results from randomized controlled trials, and adjustment was not done at an individual patient level. By including only studies published 
in English, we may have missed other relevant studies. The weak description of the intervention strategy in most studies precluded the analysis of some potentially relevant components. Notably, we were unable to study the effect of the degree of the primary care physician's involvement in these programs, which is an essential aspect for implementation. For some components, such as frequency of patient contact, we contacted the authors for more details. However, because some trials were performed several years ago, no supplementary information was available. Another limitation was the short follow-up in many of the trials, even though we excluded trials with less than 12 weeks of follow-up. Because only five trials continued for more than 12 months, we were unable to capture the long-term effects of disease-management programs. However, outcomes such as long-term diabetes complications, especially vascular complications, have not yet been examined in studies of disease management for improved diabetes care. In some trials, the length of the intervention was very short (less than six months in six trials) and thus may have been too short to produce any clinical benefits.

We noted heterogeneity in the overall effect estimate and performed a meta-regression analysis to determine potential sources. The two components of disease-management programs that led to significantly greater improvements in glycemic control accounted for $6.1 \%$ (frequency of contact) and $39.2 \%$ (treatment adjustment) of the variance between studies. We did not identify all sources of variance among trials, but a meta-analysis of summary data from reported studies has little capacity to do so.

Although a recurrent problem in meta-analyses is publication bias, application of asymmetry tests seemed inappropriate owing to the presence of heterogeneity. ${ }^{70}$ A previous meta-analysis reported a larger effect estimate for small studies. ${ }^{7}$ Because a higher intensity of intervention appears to be an important feature underpinning the efficacy of disease-management programs, this "size trial effect" could be due to a higher intensity of intervention in small studies. Indeed, of the 16 studies with a high frequency of patient contact in our analysis, $11(69 \%)$ were relatively small, with samples smaller than the median for the studies included (117 patients). This more intensive intervention in small studies, rather than publication bias, could explain the greater improvement in glycemic control.

\section{Conclusion}

Disease-management programs had a clinically moderate but significant impact on hemoglobin $\mathrm{A}_{1 \mathrm{C}}$ levels among adults with diabetes. Effective components of the programs were a high frequency of patient contact and the ability for disease managers to adjust treatment with or without prior physician approval. Our findings have important implications for both the current policy on the delivery of diabetes care and the direction of future research. Our work delineates a general framework with core features for effective programs for disease management. Priority should be given to programs with intensive and proactive follow-up that target patients at high risk of diabetes complications rather than to programs with low frequency of contact that target the overall population of patients with diabetes. In addition, disease managers should be allowed to start or modify medical treatment proactively.

More research is needed concerning the longterm impact of disease-management programs on glycemic control, microvascular and macrovascular complications, admission to hospital and mortality. Further research should also determine whether, in addition to patients with nonstabilized diabetes, other groups of patients with diabetes would benefit from disease management. Lastly, high-quality cost-effectiveness studies of disease-management programs are needed to direct care providers and policy-makers in the allocation of health care resources.

\section{References}

1. Global Guideline for Type 2 Diabetes: recommendations for standard, comprehensive, and minimal care. Diabet Med 2006;23:579-93.

2. Feder G, Griffiths C, Highton C, et al. Do clinical guidelines introduced with practice based education improve care of asthmatic and diabetic patients? A randomised controlled trial in general practices in east London. BMJ 1995;311:1473-8.

3. Davis DA, Taylor-Vaisey A. Translating guidelines into practice. A systematic review of theoretic concepts, practical experience and research evidence in the adoption of clinical practice guidelines. CMAJ 1997;157:408-16.

4. Coster S, Gulliford MC, Seed PT, et al. Self-monitoring in type 2 diabetes mellitus: a meta-analysis. Diabet Med 2000;17:755-61.

5. Vermeire E, Wens J, Van Royen P, et al. Interventions for improving adherence to treatment recommendations in people with type 2 diabetes mellitus. Cochrane Database Syst Rev 2005;CD003638.

6. Farmer A, Gibson OJ, Tarassenko L, et al. A systematic review of telemedicine interventions to support blood glucose selfmonitoring in diabetes. Diabet Med 2005;22:1372-8.

7. Shojania KG, Ranji SR, McDonald KM, et al. Effects of quality improvement strategies for type 2 diabetes on glycemic control: a meta-regression analysis. JAMA 2006;296:427-40.

8. Chodosh J, Morton SC, Mojica W, et al. Meta-analysis: chronic disease self-management programs for older adults. Ann Intern Med 2005; 143:427-38

9. Richter B, Berger M. Randomized controlled trials remain fundamental to clinical decision making in Type II diabetes mellitus: a comment to the debate on randomized controlled trials (For debate). Diabetologia 2000;43:528-32.

10. Nathan DM, Turgeon H, Regan S. Relationship between glycated haemoglobin levels and mean glucose levels over time. Diabetologia 2007;50:2239-44.

11. DerSimonian R, Laird N. Meta-analysis in clinical trials. Control Clin Trials 1986;7:177-88.

12. Higgins JP, Thompson SG. Quantifying heterogeneity in a metaanalysis. Stat Med 2002;21:1539-58.

13. Rücker G, Schwarzer G, Carpenter JR, et al. Undue reliance on $\mathrm{I}(2)$ in assessing heterogeneity may mislead. BMC Med Res Methodol 2008;8:79. 
14. Jüni $\mathrm{P}$, Witschi $\mathrm{A}$, Bloch $\mathrm{R}$, et al. The hazards of scoring the quality of clinical trials for meta-analysis. JAMA 1999;282: 1054-60.

15. Jüni $\mathrm{P}$, Altman DG, Egger M. Systematic reviews in health care: Assessing the quality of controlled clinical trials. BMJ 2001;323: 42-6.

16. Ryan R, Hill S, Broclain D, et al. Cochrane Consumers and Communication Review Group: study quality guide. Victoria (Australia); 2007.

17. Liberati A, Altman DG, Tetzlaff J, et al. The PRISMA statement for reporting systematic reviews and meta-analyses of studies that evaluate health care interventions: explanation and elaboration. Ann Intern Med 2009;151:W65-94.

18. Aubert RE, Herman WH, Waters J, et al. Nurse case management to improve glycemic control in diabetic patients in a health maintenance organization. A randomized, controlled trial. Ann Intern Med 1998;129:605-12.

19. Groeneveld Y, Petri H, Hermans J, et al. An assessment of structured care assistance in the management of patients with type 2 diabetes in general practice. Scand J Prim Health Care 2001;19: 25-30.

20. Gary TL, Batts-Turner M, Yeh HC. The effects of a nurse case manager and a community health worker team on diabetic control, emergency department visits, and hospitalizations among urban African Americans with type 2 diabetes mellitus: a randomized controlled trial. Arch Intern Med 2009;169:1788-94.

21. Estey AL, Tan MH, Mann K. Follow-up intervention: its effect on compliance behavior to a diabetes regimen. Diabetes Educ 1990;16:291-5.

22. Ahring KK, Ahring JP, Joyce $\mathrm{C}$, et al. Telephone modem access improves diabetes control in those with insulin-requiring diabetes. Diabetes Care 1992;15:971-5.

23. Franz MJ, Monk A, Barry B, et al. Effectiveness of medica nutrition therapy provided by dietitians in the management of non-insulin-dependent diabetes mellitus: a randomized, controlled clinical trial. J Am Diet Assoc 1995;95:1009-17.

24. Weinberger M, Kirkman MS, Samsa GP, et al. A nursecoordinated intervention for primary care patients with noninsulin-dependent diabetes mellitus: impact on glycemic contro and health-related quality of life. J Gen Intern Med 1995;10:59-66.

25. Jaber LA, Halapy H, Fernet M, et al. Evaluation of a pharmaceutical care model on diabetes management. Ann Pharmacother 1996;30:238-43.

26. Fukuda H, Muto T, Kawamori R. Evaluation of a diabetes patient education program consisting of a three-day hospitalization and a six-month follow-up by telephone counseling for mild diabetes and IGT. Environ Health Prev Med 1999;4:122-9.

27. Gaede P, Vedel P, Parving HH, et al. Intensified multifactorial intervention in patients with type 2 diabetes mellitus and microalbuminuria: the Steno type 2 randomised study. Lancet 1999;353:617-22.

28. Ridgeway NA, Harvill DR, Harvill LM, et al. Improved control of type 2 diabetes mellitus: a practical education/behavior modification program in a primary care clinic. South Med J 1999;92: 667-72.

29. Sadur CN, Moline N, Costa M, et al. Diabetes management in a health maintenance organization. Efficacy of care management using cluster visits. Diabetes Care 1999;22:2011-7.

30. Thompson DM, Kozak SE, Sheps S. Insulin adjustment by a diabetes nurse educator improves glucose control in insulin-requiring diabetic patients: a randomized trial. CMAJ 1999;161:959-62

31. Piette JD, Weinberger M, McPhee SJ, et al. Do automated calls with nurse follow-up improve self-care and glycemic control among vulnerable patients with diabetes? Am J Med 2000;108: 20-7.

32. Hiss RG, Gillard ML, Armbruster BA, et al. Comprehensive evaluation of community-based diabetic patients: effect of feedback to patients and their physicians: a randomized controlled trial. Diabetes Care 2001;24:690-4.

33. Piette JD, Weinberger M, Kraemer FB, et al. Impact of automated calls with nurse follow-up on diabetes treatment outcomes in a Department of Veterans Affairs Health Care System: a randomized controlled trial. Diabetes Care 2001;24:202-8.

34. Litaker D, Mion L, Planavsky L, et al. Physician-nurse practitioner teams in chronic disease management: the impact on costs, clinical effectiveness, and patients' perception of care. $J$ Interprof Care 2003;17:223-37.

35. Oh JA, Kim HS, Yoon KH, et al. A telephone-delivered intervention to improve glycemic control in type 2 diabetic patients. Yonsei Med J 2003;44:1-8.

36. Polonsky WH, Earles J, Smith S, et al. Integrating medical management with diabetes self-management training: a randomized control trial of the Diabetes Outpatient Intensive Treatment program. Diabetes Care 2003;26:3048-53.
37. Taylor CB, Miller NH, Reilly KR, et al. Evaluation of a nursecare management system to improve outcomes in patients with complicated diabetes. Diabetes Care 2003;26:1058-63.

38. Gary TL, Bone LR, Hill MN, et al. Randomized controlled trial of the effects of nurse case manager and community health worker interventions on risk factors for diabetes-related complications in urban African Americans. Prev Med 2003;37:23-32.

39. Goudswaard AN, Stolk RP, Zuithoff NP, et al. Long-term effects of self-management education for patients with type 2 diabetes taking maximal oral hypoglycaemic therapy: a randomized trial in primary care. Diabet Med 2004;21:491-6.

40. California Medi-Cal Type 2 Diabetes Study Group. Closing the gap: effect of diabetes case management on glycemic control among low-income ethnic minority populations: the California Medi-Cal Type 2 Diabetes Study. Diabetes Care 2004;27:95-103.

41. Ko GT, Li JK, Kan EC, et al. Effects of a structured health education programme by a diabetic education nurse on cardiovascular risk factors in Chinese type 2 diabetic patients: a 1-year prospective randomized study. Diabet Med 2004;21:1274-9.

42. Krein SL, Klamerus ML, Vijan S, et al. Case management for patients with poorly controlled diabetes: a randomized trial. Am J Med 2004;116:732-9

43. Montori VM, Helgemoe PK, Guyatt GH, et al. Telecare for patients with type 1 diabetes and inadequate glycemic control: a randomized controlled trial and meta-analysis. Diabetes Care 2004;27:1088-94.

44. Choe HM, Mitrovich S, Dubay D, et al. Proactive case management of high-risk patients with type 2 diabetes mellitus by a clinical pharmacist: a randomized controlled trial. Am J Manag Care 2005; 11:253-60.

45. Farmer AJ, Gibson OJ, Dudley C, et al. A randomized controlled trial of the effect of real-time telemedicine support on glycemic control in young adults with type 1 diabetes. Diabetes Care 2005;28:2697-702.

46. Menard J, Payette H, Baillargeon JP, et al. Efficacy of intensive multitherapy for patients with type 2 diabetes mellitus: a randomized controlled trial. CMAJ 2005;173:1457-66

47. McMahon GT, Gomes HE, Hickson Hohne S, et al. Web-based care management in patients with poorly controlled diabetes. Diabetes Care 2005;28:1624-9.

48. Rothman RL, Malone R, Bryant B, et al. A randomized trial of a primary care-based disease management program to improve cardiovascular risk factors and glycated hemoglobin levels in patients with diabetes. Am J Med 2005;118:276-84.

49. Taylor KI, Oberle KM, Crutcher RA, et al. Promoting health in type 2 diabetes: nurse-physician collaboration in primary care Biol Res Nurs 2005;6:207-15

50. Gabbay RA, Lendel I, Saleem TM, et al. Nurse case management improves blood pressure, emotional distress and diabetes complication screening. Diabetes Res Clin Pract 2006;71:28-35.

51. Scott DM, Boyd ST, Stephan M, et al. Outcomes of pharmacistmanaged diabetes care services in a community health center. Am J Health Syst Pharm 2006;63:2116-22.

52. Shea S, Weinstock RS, Starren J, et al. A randomized trial comparing telemedicine case management with usual care in older, ethnically diverse, medically underserved patients with diabetes mellitus. J Am Med Inform Assoc 2006;13:40-51.

53. Shibayama T, Kobayashi K, Takano A, et al. Effectiveness of lifestyle counseling by certified expert nurse of Japan for noninsulin-treated diabetic outpatients: a 1-year randomized controlled trial. Diabetes Res Clin Pract 2007;76:265-8.

54. Hiss RG, Armbruster BA, Gillard ML, et al. Nurse care manager collaboration with community-based physicians providing diabetes care: a randomized controlled trial. Diabetes Educ 2007; 33:493-502.

55. Ko SH, Song KH, Kim SR, et al. Long-term effects of a structured intensive diabetes education programme (SIDEP) in patients with type 2 diabetes mellitus - a 4-year follow-up study. Diabet Med 2007;24:55-62.

56. Wattana C, Srisuphan W, Pothiban L, et al. Effects of a diabetes self-management program on glycemic control, coronary heart disease risk, and quality of life among Thai patients with type 2 diabetes. Nurs Health Sci 2007;9:135-41.

57. Sun J, Wang Y, Chen X, et al. An integrated intervention program to control diabetes in overweight Chinese women and men with type 2 diabetes. Asia Pac J Clin Nutr 2008;17:514-24.

58. Dale J, Caramlau I, Sturt J, et al. Telephone peer-delivered intervention for diabetes motivation and support: the telecare exploratory RCT. Patient Educ Couns 2009;75:91-8.

59. Doucette WR, Witry MJ, Farris KB, et al. Community pharmacist-provided extended diabetes care. Ann Pharmacother 2009; 43:882-9.

60. Kim MT, Han HR, Song HJ, et al. A community-based, culturally tailored behavioral intervention for Korean Americans with 
type 2 diabetes. Diabetes Educ 2009;35:986-94.

61. Samuel-Hodge CD, Keyserling TC, Park S, et al. A randomized trial of a church-based diabetes self-management program for African Americans with type 2 diabetes. Diabetes Educ 2009; 35:439-54.

62. Higgins JP, Thompson SG, Deeks JJ, et al. Measuring inconsistency in meta-analyses. BMJ 2003;327:557-60.

63. Stratton IM, Adler AI, Neil HA, et al. Association of glycaemia with macrovascular and microvascular complications of type 2 diabetes (UKPDS 35): prospective observational study. BMJ 2000;321:405-12.

64. Hayward RA, Manning WG, Kaplan SH, et al. Starting insulin therapy in patients with type 2 diabetes: effectiveness, complications, and resource utilization. JAMA 1997;278:1663-9.

65. Ho PM, Rumsfeld JS, Masoudi FA, et al. Effect of medication nonadherence on hospitalization and mortality among patients with diabetes mellitus. Arch Intern Med 2006;166:1836-41.

66. Brown SA. Studies of educational interventions and outcomes in diabetic adults: a meta-analysis revisited. Patient Educ Couns 1990;16:189-215

67. Ellis SE, Speroff T, Dittus RS, et al. Diabetes patient education a meta-analysis and meta-regression. Patient Educ Couns 2004; 52:97-105.

68. Knight K, Badamgarav E, Henning JM, et al. A systematic review of diabetes disease management programs. Am J Manag Care 2005;11:242-50.

69. Norris SL, Nichols PJ, Caspersen CJ, et al. The effectiveness of disease and case management for people with diabetes. A systematic review. Am J Prev Med 2002;22:15-38.

70. Ioannidis JP, Trikalinos TA. The appropriateness of asymmetry tests for publication bias in meta-analyses: a large survey. CMAJ 2007;176:1091-6.

Competing interests: Catherine Helmer has received grants from the Agence nationale de la recherche and the Institut national de prévention et d'education pour la santé; honoraria from Eisai Inc., Pfizer Inc. and Ipsen; and royalties from Edimark for an article on an unrelated topic. Rodolphe Thiébaut is a member of the advisory board for Gilead. No competing interests declared by Clément Pimouguet, Mélanie Le Goff or Jean François Dartigues.

Affiliations: From the Institut national de la santé et de la recherche médicale (Pimouguet, Le Goff, Thiébaut, Dartigues, Helmer); the Université Victor Segalen Bordeaux 2 (Pimouguet, Le Goff, Thiébaut, Dartigues, Helmer); and the Centre hospitalier universitaire de Bordeaux (Dartigues), Bordeaux, France

Contributors: Clément Pimouguet and Catherine Helmer designed the study, completed the literature search, extracted the data and drafted the manuscript. Mélanie Le Goff contributed to the data extraction, performed the data analysis and helped with the revision of the manuscript. Rodolphe Thiébaut helped with the interpretation of the results, and the consolidation and revision of the manuscript. Jean François Dartigues assisted with the design of the study, contributed to the interpretation of the results and helped with the consolidation and revision of the last draft of the manuscript. All of the authors approved the final version of the manuscript.

Funding: This study was funded by the French Ministry of Health. The ministry had no role in the design of the study, the analysis or interpretation of the data, or the writing of the manuscript.

Acknowledgements: The authors acknowledge the assistance of Evelyne Mouillet, Coralie Thore and Christian Weller from the documentary centre of the Institut de santé publique, d'épidémiologie et de développement. 


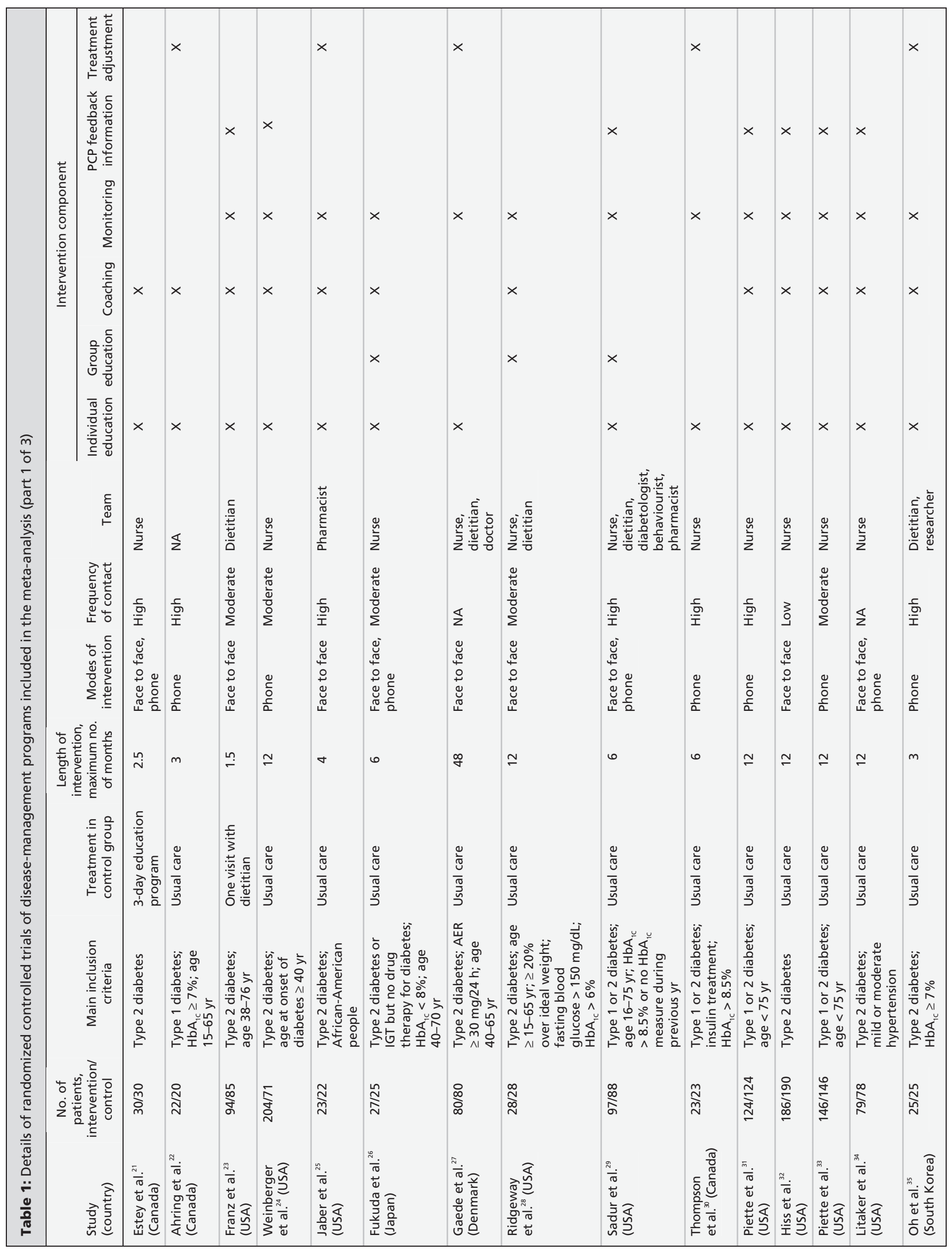




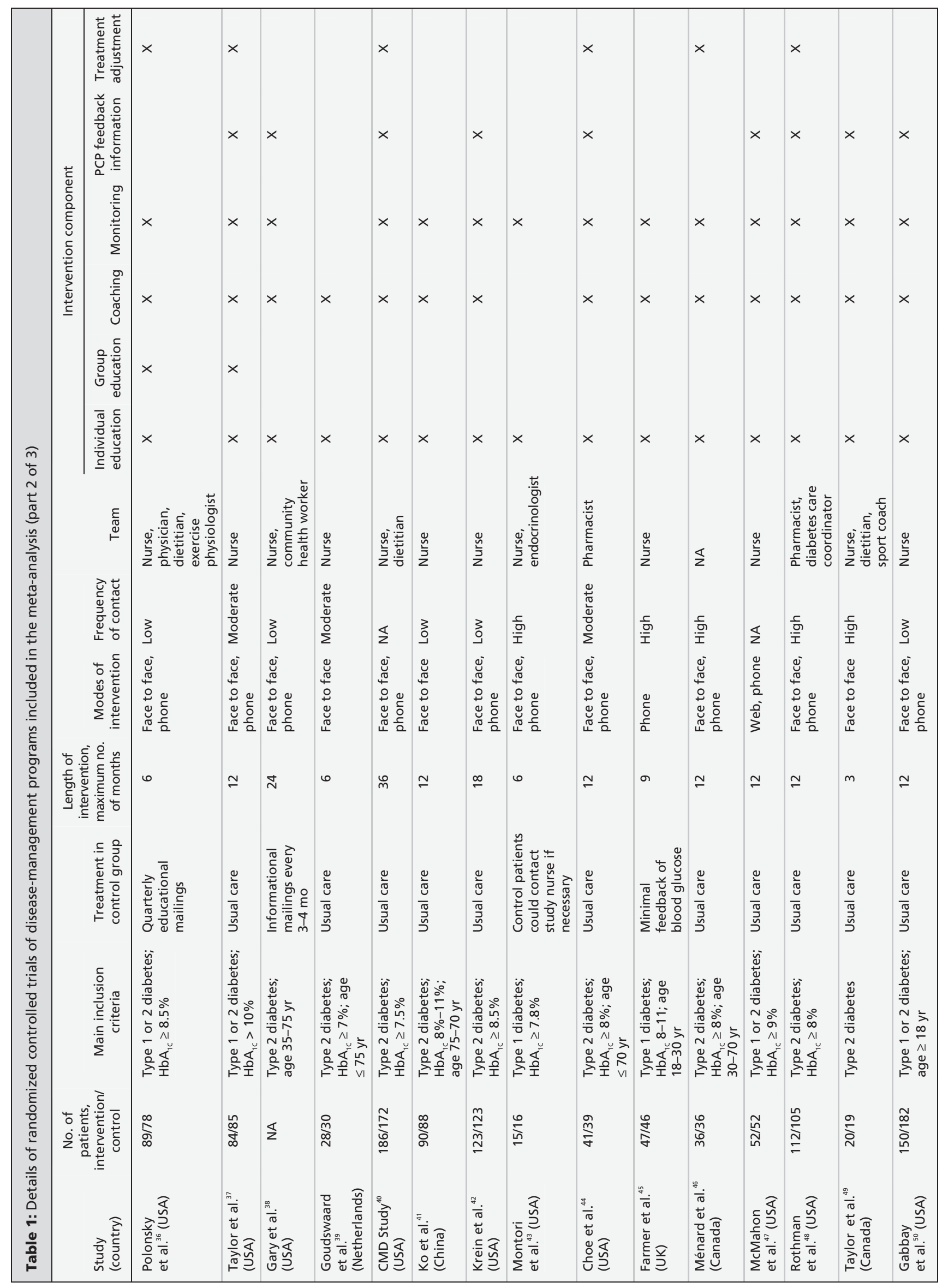




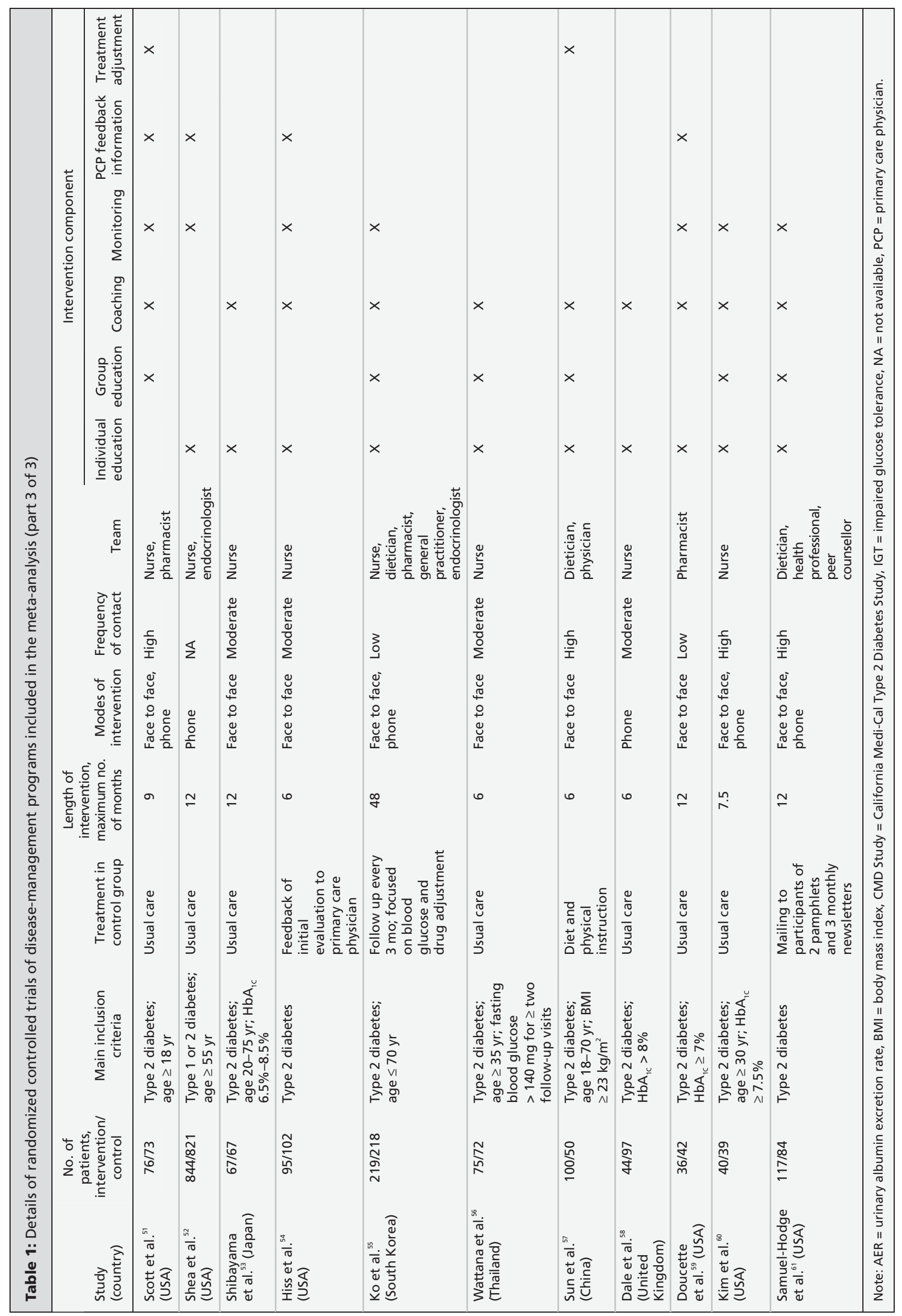

